\title{
Construção de vocabulários multilíngues: perspectivas culturais
}

\author{
Ricardo Biscalchin \\ http://orcid.org/0000-0001-8099-206X \\ Walter Moreira ${ }^{I I}$ \\ http://orcid.org/0000-0001-9454-441X \\ I Universidade Estadual Paulista, SP, Brasil. \\ Doutorando no Programa de Pós-Graduação em Ciência da Informação. \\ ${ }^{\text {II }}$ Universidade Estadual Paulista, SP, Brasil. \\ Docente no Programa de Pós-Graduação em Ciência da Informação.
}

http://dx.doi.org/10.1590/1981-5344/3690

A Ciência da Informação busca organizar e disseminar a informação de modo eficaz, ético e igualitário. Romper as barreiras linguísticas e culturais no acesso e representação da informação, via construção de vocabulários controlados multilíngues que sigam os conceitos da transculturalidade, da multiculturalidade e da garantia cultural é uma maneira de atender a esses propósitos. O objetivo desta pesquisa é apresentar esses conceitos e demonstrar a importância de sua aplicação no momento da construção de vocabulários multilíngues para que diferentes culturas tenham acesso à informação de maneira igualitária e justa. Para tanto, realizou-se uma análise teórica de normas técnicas e publicações científicas sobre a temática para demonstrar a importância da aplicação conjunta desses conceitos para a representação da informação. Este artigo consiste, portanto, na discussão da importância das reações entre esses conceitos, teorias e normas para aplicação na construção de vocabulários multilíngues, visando a construção de representações condizentes com a realidade sócio-histórico-cultural dos diferentes usuários. 
Conclui-se que a aplicação da transculturalidade, multiculturalidade e garantia cultural em conjunto com as normas e estudos científicos sobre construção de vocabulários multilíngues constitui-se como elemento fundamental para viabilizar a construção e o uso de representação terminológica da informação que respeite heterogeneidade das diversidades culturais.

Palavras-chave: Vocabulário Controlado Multilíngue. Transculturalidade. Multiculturalidade. Garantia Cultural. Organização do Conhecimento.

\section{Construction of multilingual vocabulary: cultural perspectives}

Information Science seeks to organize and disseminate information in an effective, ethical and equally way. Breaking with linguistic and cultural barriers in accessing and representing information, through the construction of multilingual controlled vocabularies that follow the concepts of transculturality, multiculturality and cultural warranty is a way of meeting these objectives. The aim of this research is to present these concepts and demonstrate the importance of their application when building multilingual vocabularies for equal and fair access between different cultures. A theoretical analysis of technical standards and scientific publications on the subject was carried out to demonstrate the importance of the joint application of these concepts for the representation of information. This paper consists of discussing the importance of the relationship between these concepts, theories and norms for application in the construction of multilingual vocabularies, for a representation consistent with the socio-historical-cultural reality of the users. It is concluded that the application of transculturality, multiculturality and cultural guarantee in conjunction with the norms and scientific studies on the construction of multilingual vocabularies enables the terminological representation of information in each 
language, so that it contemplates the socio-historicalcultural context of each user, in an equally and fairly.

Keywords: Multilingual Controlled Vocabulary.
Transculturality. Multiculturalism. Cultural Warranty.
Knowledge Organization.

Recebido em 05.10.2018Aceito em 16.11.2020

\section{Introdução}

No atual contexto sócio-histórico-cultural, a tecnologia encurtou distâncias possibilitando a comunicação instantânea entre indivíduos e acesso amplo a diversas fontes de informação em diferentes línguas e culturas. Tratando-se especificamente dos avanços possibilitados pelo uso das tecnologias da informação e comunicação, para além da superação das barreiras geográficas relativas ao acesso aos documentos, ainda há muito para se investigar e agir em relação às barreiras linguísticas e culturais.

A Ciência da Informação tem como um dos seus principais objetivos a organização e a disseminação da informação de maneira eficaz, ética e igualitária. Um modo possível de atender a esses objetivos relaciona-se, senão ao rompimento, pelo menos à diminuição das barreiras linguísticas e culturais que interferem nas ações de representação da informação, tanto aquelas que o indexador realiza quanto as que o usuário faz. As interações entre as representações documentárias produzidas pelo usuário e aquelas que são construídas pelo indexador realizam-se, em situação ideal, com o auxílio de instrumentos de vocabulários controlados. Desse modo, não se configura como produtiva a concepção de vocabulários controlados que não sejam multilíngues ou que não sigam os preceitos da transculturalidade, da multiculturalidade e da garantia cultural, levando-se em consideração o contexto globalizado de compartilhamento de informação principalmente via web e as características cada vez mais difusas do que se convencionou denominar "comunidade usuária".

Segundo Olson (2002, p. 6) um vocabulário controlado é um conjunto de termos ou notações com três características:"1) um vocabulário limitado, do qual um indexador ou catalogador escolhe, de modo exclusivo, termos para descrever o conteúdo do assunto de um documento; 2) um e apenas um termo ou notação para cada conceito; e 3) uma estrutura que define as relações entre os conceitos". 
Entende-se que os vocabulários controlados multilíngues não consistem em uma simples tradução ou a união de diversos vocabulários monolíngues por agrupamento, mas sim em um trabalho conceitual e representativo da realidade sócio-histórico-cultural concernente a cada língua a ser representada, tanto hierarquicamente como terminologicamente.

A combinação das perspectivas sócio-histórico-culturais na construção de vocabulários multilíngues irá possibilitar a representação da informação da maneira mais próxima à realidade do usuário, buscando eliminar relações terminológicas e estruturas hierárquicas não adequadas, evitando a exclusão de minorias sociais e o preconceito ou imposição de valores culturais.

Chama-se de estruturas não adequadas a construção hierárquica de relações não existentes na língua representada, sendo desse modo, incompatíveis com essa língua e estranhas aos falantes dela. Um vocabulário controlado, vale lembrar, é uma linguagem artificial, construída para a representação de uma linguagem natural, que deve, primeiramente, respeitar a estrutura lexical dessa língua por meio de termos controlados.

A noção de cultura, quando aplicada ao domínio da classificação tem implicações significativas e diversas a respeito da representação do conhecimento e da maneira como os usuários se relacionam com os termos de indexação e com as formas de organização dos documentos (BARITÉ, 2011).

Beghtol (2002a, p. 509) afirma que a cultura é

transdisciplinar e descreve em geral os vários fenômenos que compõem as crenças e atividades coletivas de algum grupo de pessoas. As discussões sobre a cultura geralmente se referem a valores compartilhados, história, linguagem, memória coletiva, atitudes sociais, preferências e práticas, entre outros. (BEGHTOL, 2002a, p. 509).

A cultura se encontra associada a uma comunidade de indivíduos que compartilham valores, crenças e costumes. Essas comunidades que anteriormente se prendiam mais a contextos geográficos, hoje com 0 advento da internet, romperam fronteiras e se apresentam em grupos que em muitos casos jamais se encontraram fisicamente. Um exemplo é a comunidade gee $k$, termo utilizado atualmente para representar o conceito de pessoas interessadas em assuntos científicos, tecnologia e que gostam de estudar. Essa comunidade, apesar de se encontrar em alguns eventos, científicos ou não, e compartilhar interesses e modos de compreensão do mundo, constituiu-se e se consolidou de modo desterritorializado por meio das redes sociais, mantendo muitas de suas atividades via web, não pertencendo a um contexto geográfico específico, mas sim global. Muitos 
desses indivíduos jamais se encontrarão presencialmente, mas compartilham de uma mesma cultura e compreensão do mundo.

É importante considerar que "os limites dentro de uma cultura podem ser vagos e criar conflitos ou tensões culturais. Por isso, enquanto sociedade, os indivíduos podem ser multiculturais, multilíngues e participar de atividades multidisciplinares" (BEGHTOL, 2002a, p. 509).

Mediante este cenário de ampla diversidade cultural e conectividade de diferentes culturas e realidades sociais, esta pesquisa tem como objetivo apresentar e discutir as possibilidades de construção de vocabulários controlados multilíngues em diálogo com os conceitos de transculturalidade, multiculturalidade e garantia cultural. Esse objetivo encontra justificativa em um dos princípios basilares da ciência da informação que se relaciona à promoção de condições de acesso à informação de maneira eficiente e igualitária, sem distinções por etnias, crenças ou contextos sócio-histórico-culturais.

O contexto sócio-histórico-cultural consiste no reconhecimento do momento histórico, do contexto social a que os usuários pertencem e por fim, a identificação cultural desses usuários. Essa análise possibilita o entendimento da identidade cultural desse usuário, possibilitando a busca e seleção de termos mais adequados a esses usuários.

Para o desenvolvimento da pesquisa, realizou-se uma pesquisa bibliográfica sobre os conceitos de transculturalidade, multiculturalidade, garantia cultural e vocabulário controlado, buscando contextualizá-los para uso e aplicação na construção de vocabulários multilíngues.

A necessidade da inclusão dos conceitos culturais na construção de vocabulários multilíngues justifica-se pela importância da identificação do usuário com a informação representada no vocabulário, o que se relaciona de modo direto com as questões que envolvem a língua e sua estrutura hierárquica e terminológica.

A construção de vocabulários controlados cujos processos de seleção de termos não manifesta preocupação cultural explícita, incorre no risco de realizar representações "estranhas" aos usuários, o que acarreta a falta de credibilidade do sistema como consequência da inadequação da representação da informação apresentada.

\section{A transculturalidade, a multiculturalidade, a garantia cultural e a possibilidade de construção de vocabulários controlados multilíngues}

Nesta seção aborda-se a transculturalidade, a multiculturalidade e a garantia cultural na perspectiva de sua aplicação na construção de vocabulários controlados multilíngues.

\subsection{A transculturalidade}


A transculturalidade segundo López-Huertas (2007, p.4) considera a realidade estruturada em múltiplos níveis, substituindo a visão de uma realidade unidimensional do pensamento clássico.

A transculturalidade apoia-se na intersecção entre diversas culturas. Como resultante desta intersecção, torna-se muitas vezes muito difícil identificar a origem cultural (no sentido de determinar um ponto mais ou menos exato) de um termo, costume ou até mesmo de um conceito. "A transculturalidade fundamenta-se na interação, isto é, no intercâmbio acelerado, global, descentralizado e atemporal de valores e categorias desarraigadas e procedentes de geoculturas em dissolução e de cada vez mais complexa rastreabilidade" (GARCÍAGUTIÉRREZ, 2014, p.14).

A transculturalidade rompe fronteiras apresentando-se por meio de uma diversidade cultural na qual

cada indivíduo pode potencialmente pertencer a várias culturas em vários níveis diferentes. Por exemplo, uma pessoa pode viver em um país, falar a(s) língua(s) de outro(s) país(es), aderir às políticas de um certo partido político, aderir e praticar uma certa religião e/ou pertencer a organizações sociais que atravessam fronteiras nacionais e/ou étnicas. (BEGHTOL, 2002a, p. 509).

As diferentes culturas possueminfinidades de nuances dentro de uma mesma fronteira geográfica, e com o advento da globalização, essa transculturalidade é cada vez mais presente nas realidades culturais dos mais distintos povos. Isso se mostra presente em vários aspectos, desde tecnológicos até culinários. A transculturalidade é um "[...] instrumento de interpretação da nova realidade gerada pela sociedade em rede e pelos meios de comunicação de massa de alcance global" (LUCCHESI; MALANGA, 2011, p. 82).

Desse modo, pode-se afirmar que a transculturalidade

suplanta o aspecto da compreensão de uma cultura por outra cultura e garante a tradução de uma cultura para qualquer outra cultura, por meio do sentido que une as mais diversas culturas, privilegiando a constituição de uma identidade cultural supranacional, sem a perda das identidades culturais. (BISCALCHIN; BOCCATO, 2014, p. 240).

A ética transcultural apresentada por García-Gutierrez é, de acordo com Guimarães e Pinho (2006, p. 6),

[...] o conceito principal apresentado pelo autor, cuja concepção se deu através de uma nova estrutura epistemológica social, ética e de princípios técnicos na organização e representação do conhecimento, trabalhando 
a questão da diversidade cultural e sua representação pelos sistemas de classificação, e alerta para as necessidades de que essas atividades sejam desempenhadas por profissionais, que ele denomina de mediadores, com estímulo a reflexão crítica, uma vez que os instrumentos por eles desenvolvidos não podem estar propensos a uma dada ideologia dominante. (GUIMARÃES; PINHO, 2006, p. 6).

A transculturalidade reconhece a intersecção, a "mistura" entre distintas culturas e a importância da construção de representações que expressem ou que respeitem a diversidade cultural. Moody-Adams (1994, p. 291) afirma que a "[...] capacidade de ser influenciado pela cultura específica de um determinado grupo social é uma parte importante daquilo que significa ser humano." Ser "humano", nesta acepção, relaciona-se ao fato de se comunicar e se influenciar por relações e atividades, pelo aprendizado de novas formas, por meio de contato, observação e troca de conhecimento e cultura.

A transculturalidade opera com a identidade cultural que ultrapassa fronteiras e se constitui pela combinação de culturas e pela influência de uma cultura sobre a outra, de modo que se reconheçam suas relações de complementaridade. Devidamente aplicado, o prefixo "trans" anteposto a "cultura", nação ou estado implica "tanto uma suspensão de [suas] demarcações como também uma reassociação aos mesmos" (HÜHN et al., 2010, p. 15).

A aplicação dos princípios da transculturalidade em vocabulários controlados multilíngues irá auxiliar na representação desse relacionamento intercultural, incluindo inclusive as minorias sociais, por reconhecer esse relacionamento entre diferentes culturas. Compreendese, neste contexto, como minorias sociais os grupos pouco prestigiados política e economicamente em uma sociedade, aqueles que ficam marginalizados pelo(s) grupo(s) dominante(s). Um exemplo aplicado à realidade brasileira são as diversas culturas indígenas, que têm sua voz silenciada mediante a imposição cultural de outros grupos dominantes.

Em complemento aos conceitos da transculturalidade, tem-se a multiculturalidade, que reconhece a existência de múltiplas comunidades culturais dentro de uma cultura.

\subsection{A multiculturalidade}

A multiculturalidade consiste no reconhecimento da existência de múltiplas realidades culturais, em nível global, nacional ou até mesmo de pequenos grupos, como uma vila ou uma família.

A aplicação dos princípios da multiculturalidade, no contexto da construção e manutenção de vocabulários controlados, busca o reconhecimento e representação da diversidade cultural existente dentro 
de uma cultura, de modo que minorias não sejam excluídas, ou que o conceito cultural mais influente, seja apresentado como único, como exclusivo em uma cultura.

A multiculturalidade designa a característica de sociedades formadas por múltiplas comunidades culturais, que convivem entre si (LAZZARIN, 2008). O Canadá é um exemplo de país com características multiculturais e bilinguismo, em função da influência exercida pela colonização inglesa e francesa. A realidade canadense demonstra a importância de representação conforme a especificidade de cada cultura, sendo que nesse caso, um vocabulário bilíngue se apresenta como um importante instrumento para a representação dessa multiculturalidade linguística e cultural.

O Brasil, um país de dimensões continentais, apesar de ter a língua portuguesa como língua oficial em todo o território, também convive com a multiculturalidade. A diversidade cultural brasileira ocorre desde costumes e crenças religiosas, até termos e figuras de linguagem, o que leva a necessidade de considerar todas essas variantes no momento da recolha terminológica, para que a representação da informação não seja favorável a um conjunto de usuários em detrimento de outro.

De acordo com Boccato e Biscalchin (2014, p. 240), "a multiculturalidade é representativa da diversidade cultural, e quando aplicada em vocabulários controlados multilíngues poderá criar condições de acesso para que o usuário possa encontrar e buscar a informação conforme suas percepções culturais."

Toda cultura é, por sua própria acepção, múltipla e sempre apresenta variantes que podem ser aceitas de maneira quase que igualitária por uma significativa parcela de indivíduos (em termos numéricos), ou serem simplesmente pertencentes a grupos muito pequenos ou pouco influentes economicamente, e que sem essa preocupação multicultural acabariam ficando sem representação, "sem voz".

A multiculturalidade reflete em sua essência a ética na medida em que busca a defesa de um valor maior: a inclusão, ou seja, o resguardo dos direitos de todos os cidadãos, tal como expresso na Declaração Universal dos Direitos do Homem (MILANI et al., 2009).

Em complemento ao conceito da transculturalidade, que aborda a intersecção entre distintas culturas, a multiculturalidade reconhece a existência de diferentes comunidades culturais dentro de uma cultura, e a aplicação desse reconhecimento multicultural no desenvolvimento de vocabulários controlados visa a possibilitar a construção de representações documentárias que incluam termos representativos dessa diversidade cultural.

Na sequência, aborda-se a garantia cultural. Esta, em consonância com a transculturalidade e a multiculturalidade, destaca a importância de 
que a informação seja representada da maneira mais próxima da realidade cultural dos usuários, de modo que eles reconheçam a estrutura hierárquica e a terminologia utilizada como parte de sua realidade.

\subsection{A garantia cultural}

A garantia cultural, conforme a descreve Lee (1976, p. 111-112), é "uma aplicação prática dos valores culturais expressos pela literatura produzida por uma determinada cultura", ou seja, é uma manifestação cultural da literatura de uma área de conhecimento.

A garantia literária sustenta-se na ideia central de que a literatura de um domínio deve ser a fonte de extração e validação terminológica a ser incorporada em um sistema de classificação (BARITÉ, 2009). Assim, a garantia literária tem em sua concepção o enfoque na terminologia de uma área específica de conhecimento, porém, sem se preocupar com as possíveis variantes culturais, que são complementadas pela garantia cultural.

Barité, et. al. (2010, p. 135-136) afirmam que a garantia literária

poderia ser insuficiente como única base para uma metodologia de construção de estruturas conceituais. Por isso, diversos autores propõem outras formas de garantia (garantia de usuário, garantia cultural, garantia organizacional, opinião de especialistas, etc.) para melhorar a qualidade de sistemas de classificação, de vocabulários controlados e de outras linguagens. Estas outras garantias poderiam demonstrar sua pertinência e complementaridade, enriquecendo o conceito original. (BARITÉ et al., 2010, p. 135-136).

Beghtol (2002a, p. 511) conceitua a garantia cultural afirmando que "[...] qualquer tipo de representação do conhecimento e/ou sistema de organização pode ser maximamente adequado e útil para os indivíduos em alguma cultura somente se for baseado nas suposições, valores e proposições dessa mesma cultura."

A garantia cultural contribui para a qualidade da representação da informação, quando os termos devem ser adequados ao contexto cultural que os usuários se encontram inseridos.

É importante ressaltar, conforme afirma Barité (2011, p.10), que

o conceito de garantia cultural não é neutro, como tampouco

o conceito de cultura. Através da garantia cultural se relativizam as ideias de que tanto os sistemas de organização do conhecimento como os processos de classificação e de indexação devem ser baseados na objetividade e na neutralidade, seguindo as premissas da suposta objetividade da ciência. (BARITÉ, 2011, p.10). 
A objetividade de acordo com Santos (2012, p. 100) é entendida como a característica daquele conhecimento sobre a realidade que se confunde com a própria realidade."[...] Idealiza-se, assim, o conhecimento científico como um conhecimento exato, que tem a propriedade de estabelecer afirmações inequívocas, que tem validade universal, interpretação única, independente e externa ao sujeito/pesquisador."

Essa objetividade e neutralidade que a garantia cultural busca são conflitantes com sua proposição de compreender o mundo, entende-se que o mais adequado é afirmar que a garantia cultural busca a objetivação.

Na objetivação ao contrário da objetividade,

há uma desconstrução do ideário de natureza absoluta. Não há fenômenos simples. A identificação do objeto [...] implica um saber provisório, inconcluso, incompatível com as certezas estáveis que prometia o paradigma da objetividade. O conhecimento, por sua vez, só pode constituir-se através de aproximações contínuas, viabilizadas, simultaneamente, pelo modelo teórico e pela aplicação da técnica (SANTOS, 2012, p. 100).

Assim a objetivação reconhece a influência do meio, da relação nos estudos e consequentemente na representação da informação.

A informação deve ser tratada de maneira ética e o mais neutra possível, de modo que não existam imposições culturais, sejam elas de origem geográfica (pelo compartilhamento de valores e costumes), religiosa ou de outra natureza. Para Barité (2011) a garantia cultural deve contribuir com a integração cultural, reafirmando as culturas locais e neutralizando nos sistemas de organização do conhecimento os efeitos de aculturação associados a globalização, processos políticos e econômicos de exclusão social.

Em caráter de complementaridade à aplicação do conceito de garantia cultural aos processos de representação do conhecimento, Beghtol(2005) apresenta também o conceito de hospitalidade cultural. Segundo este conceito, "a representação do conhecimento e sua disposição em sistemas de organização do conhecimento pode idealmente acomodar as várias garantias de diferentes culturas e refletir adequadamente os pressupostos de qualquer indivíduo, grupo ou comunidade" (BEGTHOL, 2005, p. 905). Ainda no mesmo texto, a autora define o conceito de hospitalidade como "a capacidade de uma notação de classificação de incorporar novos conceitos em lugares apropriados e permitir o estabelecimento de relações precisas entre os velhos e os novos conceitos." (BEGTHOL, 2005, p. 905). 
Desse modo a hospitalidade cultural possibilita o "encaixe" dos conceitos em seus "devidos lugares", permitindo o relacionamento entre conceitos "novos" e aqueles já registrados no sistema. Ela assim possibilita a aplicação de conceitos condizentes com a realidade sóciohistórico-cultural de cada área do conhecimento a ser representada, conforme a especificidade de cada língua.

A garantia cultural busca a representação da informação de maneira igualitária em todas as línguas, de modo que nenhuma se sobreponha a outra. A extração dos termos deve ocorrer em cada língua específica, e nunca por meio de traduções. A ética na recolha terminológica é necessária para o respeito a essas premissas.

A garantia cultural acaba por propor o privilégio de uma apreciação cultural parcial da realidade, para ajustar os esquemas e a terminologia de um sistema as particularidades culturais e linguísticas de uma comunidade de usuários (BARITÉ, 2011).

Sempre que se pensa em um conjunto de usuários reais e potenciais, realiza-se uma pré-seleção cultural a ser atendida, o que pode levar a exclusão de algumas culturas. A própria ignorância sobre a existência de outras culturas já se configura, nesses casos, como excludente. Assim, é preciso destacar que a garantia cultural busca a neutralidade, mas não é neutra, assim como tampouco a cultura.

Tal fato remete novamente à objetividade da ciência, o que demonstra que a garantia cultural, tomada isoladamente, não possibilita um tratamento igualitário e justo a todas as culturas, mas sim as culturas representadas pelo vocabulário, ou seja, pelo conjunto de usuários selecionados para serem usuários ou potenciais usuários do sistema. Ressalta-se, portanto, a imperiosa necessidade de combinação dos conceitos advindos da transculturalidade, da multiculturalidade e da garantia cultural para a construção de vocabulários controlados multilíngues.

A aplicação conjunta desses conceitos cria condições para que os termos adotados em cada língua sejam o mais proximamente possível equivalentes aos conceitos que devem representar, conforme o contexto sócio-histórico-cultural de cada língua, não implicando em relações, termos e estruturas hierárquicas estranhas aos usuários do sistema e /ou impositivas de uma única realidade cultural.

\subsection{Possibilidades de construção de um vocabulário controlado multilíngue}

Antes de abordar a construção de um vocabulário controlado multilíngue, deve-se ressaltar a importância do vocabulário controlado, que de acordo com a norma ISO 25.964 (2011, p. 12) consiste em um "conjunto organizado de termos, cabeçalhos ou códigos que representam 
conceitos e suas inter-relações, que podem ser usados para apoiar a recuperação de informações".

Resgatando-se a definição de Olson (2002), tem-se que um vocabulário controlado é um conjunto de termos ou notações com três características: a) é um vocabulário limitado; b) utiliza um e apenas um termo ou notação para cada conceito; c) é uma estrutura que define as relações entre os conceitos. Em relação ao seu potencial semântico, espera-se, idealmente, que um vocabulário controlado represente, por meio de uma estrutura terminológica, os sistemas conceituais referentes aos diversos domínios de conhecimento. Inserindo-se no vocabulário controlado o contexto multilíngue em conjunto com as premissas da transculturalidade, da multiculturalidade e da garantia cultural, as estruturas hierárquicas desse vocabulário devem contemplar as especificidades de cada língua e cultura.

A construção de vocabulários multilíngues implica diversos cuidados, que são discutidos por diversos pesquisadores e subsidiados por um conjunto de normas e diretrizes. Para atender as perspectivas da transculturalidade, multiculturalidade e da garantia cultural, o vocabulário controlado multilíngue deve, conforme apresentam Hudon (1997), a norma da IFLA 115 - Guidelines for Multilingual Thesauri (2009)e a norma ISO 25.964 (2011), ser organizado hierarquicamente de maneira distinta e assimétrica, ou seja, o número de termos e a disposição hierárquica podem variar de uma língua para a outra conforme a especificidade presente em cada língua e cultura.

A simetria no vocabulário multilíngue consiste em escolher uma língua como modelo (fonte) e replicar sua estrutura hierárquica nas demais línguas (alvo), o que pode aumentar a artificialidade do vocabulário criando relações inexistentes em uma língua alvo para preservar a simetria existente na língua fonte.

Sobre a construção do vocabulário multilíngue a norma ISO 25.964 (2011, p. 92) apresenta três abordagens:

1. tradução de um vocabulário monolíngue;

2. fusão de distintos vocabulários monolíngues;

3. construção simultânea de várias versões linguísticas do vocabulário multilíngue.

Ainda em relação à construção de vocabulários multilíngues, Hudon (1997) acrescenta que os vocabulários relativos às diferentes línguas devem ser desenvolvidos preferencialmente de maneira simultânea, contando com a colaboração de uma equipe qualificada composta por membros nativos de cada língua a ser representada. Essa perspectiva de construção é essencial para garantir o respeito à diversidade cultural 
existente em cada língua, possibilitando a representação da informação conforme a especificidade presente em cada língua e cultura. A ideia da simultaneidade visa justamente ao tratamento igualitário das diversas línguas, sem que se tome uma delas como língua fonte. A norma ISO 25.964 (2011, p. 92) corrobora essa afirmação: "a construção simultânea permite que todas as línguas do vocabulário tenham o mesmo status. Cada língua se torna língua fonte e língua de alvo, podendo ter impacto sobre o estabelecimento de relacionamentos hierárquicos e associativos."

A representação dos termos em cada língua deve basear-se nas convenções aplicadas nessa língua. Como consequência de tal prática, um vocabulário multilíngue "é suscetível de ter entradas em que um termo no singular em francês ou em alemão tem um equivalente em inglês no plural" (ISO 25.964, 2011, p. 27).

Sobre as perspectivas de construção de vocabulários multilíngues, a ISO 25.964 (2011) apresenta três abordagens, e destaca que a escolha delas está condicionada aos recursos humanos, de tempo e financeiros, além do contexto de aplicação, que pode já possuir, por exemplo, um vocabulário monolíngue. As perspectivas de construção apresentadas pela ISO 25.964 (2011, p. 92) são:

a) tradução de um vocabulário monolíngue - a abordagem de tradução é uma maneira popular e relativamente econômica de construir um vocabulário multilíngue. É especialmente rentável se os documentos a serem pesquisados já tiverem sido indexados com o tesauro monolíngue. No entanto, se essa abordagem for adotada a linguagem do vocabulário monolíngue original adquire o status de língua dominante;

b) fusão de distintos tesauros monolíngues - a fusão de distintos vocabulários monolíngues é um processo complexo. É mais respeitoso com a integridade dos diferentes sistemas conceituais e linguísticos que devem ser reconciliados, permitindo que todas as línguas assumam o papel da linguagem de origem;

c) construção simultânea das várias versões linguísticas do vocabulário multilíngue - esta terceira abordagem permite que todas as línguas do vocabulário tenham o mesmo status. Cada língua se torna língua fonte e língua alvo, e por sua vez pode ter um impacto sobre o estabelecimento de relacionamentos hierárquicos e associativos.

Hudon (1997) defende a opção "c" como a mais adequada para a construção de vocabulários controlados multilíngues que atendam as demandas culturais em cada língua. Essa opção se apresenta como a mais compatível com as premissas da transculturalidade, da multiculturalidade e da garantia cultural, por permitir que cada língua receba um tratamento equivalente, sem a escolha de uma língua como fonte para embasamento da construção hierárquica do vocabulário. 
Essa preocupação com a estrutura no momento da construção do vocabulário multilíngue é essencial para a aplicação dos conceitos da transculturalidade, da multiculturalidade e da garantia cultural, pois conforme afirma Hudon (1997, p. 114) um vocabulário multilíngue que "se estruture baseado apenas em uma língua, fornecendo apenas descritores equivalentes para as outras línguas, sem uma estrutura semântica completa, não se constitui em um verdadeiro vocabulário multilíngue."

Um vocabulário controlado multilíngue, mais que a simples tradução terminológica, busca o termo mais adequado para a representação do conceito, conforme a especificidade de cada língua, procurando se adequar hierárquica e estruturalmente a cada língua.

De acordo com a norma ISO 25.964 (2011. p. 50)

também é possível tratar diferentes dialetos ou sublínguas como se fossem línguas distintas. Por exemplo, o inglês americano, o inglês britânico e o inglês indiano podem ser tratados como línguas distintas, todas as três apresentadas separadamente em um vocabulário trilíngue. Muitos dos termos são comuns a duas ou três línguas, mas outros termos são diferentes. (ISO, 2011, p.50).

De acordo com Guimarães e Pinho (2006), Hudon (1997) apresentou por meio da sua concepção de multilinguagem, uma proposta relevante para a ética na representação do conhecimento. O tratamento igualitário entre as línguas que participam de um vocabulário multilíngue é o eixo que permite uma visão ética na concepção de instrumentos de representação.

Para alcançar a representação ética e igualitária da informação em diferentes línguas, devemos, de acordo com Hudon (1999, p. 159), evitar três procedimentos:

1) estender uma linguagem para fazê-la "encaixar" em uma estrutura conceitual estranha ao ponto de se tornar irreconhecível aos seus próprios falantes; 2) transferir a estrutura conceitual de uma cultura para outra, sem analisar se ela é apropriada ou não; 3) traduzir literalmente os termos da língua-fonte para expressões sem sentido na(s) língua(s)-alvo.

A aplicação de qualquer um desses procedimentos vai contra os preceitos culturais apresentados, ferindo o objetivo principal a ser alcançado, que é a disseminação da informação de uma maneira igualitária e justa a todos os usuários do sistema, conforme seu contexto sócio-histórico-cultural, evitando a imposição de uma cultura sobre as demais, distribuindo o acesso à ciência e ao conhecimento científico de maneira ampla e igualitária. 
$\mathrm{Na}$ representação terminológica, existem diferentes graus de equivalência. A norma ISO 25.964 (2011. p. 51) apresenta quatro possibilidades:

Equivalência exata - Nesta situação ideal, um conceito é representado em todas as línguas de um vocabulário multilíngue, e é possível identificar termos preferidos semanticamente e culturalmente equivalentes. Uma relação de equivalência entre línguas deve ser estabelecida entre os termos preferidos correspondentes.

Equivalência inexata ou quase equivalência - Os termos encontrados em diferentes línguas às vezes carregam uma pequena diferença no escopo, talvez devido a diferenças culturais, de conotação ou de apreciação. Se, no entanto, os termos são aceitos como próximos o suficiente para representar o mesmo conceito quando usado no vocabulário, então um termo preferido para cada língua deve ser selecionado, a equivalência entre eles estabelecida e o escopo do conceito entendido como incluindo todas as variações culturais.

Equivalência parcial (também conhecida como equivalência mais geral/ mais específica) - Às vezes, uma língua não possui um termo que represente com precisão o conceito para o qual um rótulo é procurado, mas possui um termo que normalmente é considerado como representando um conceito mais específico ou mais geral. Se o escopo do conceito representado por um termo cai completamente dentro do escopo do conceito representado pelo outro, os termos são considerados parcialmente equivalentes. Se a diferença de escopo for pequena o suficiente, pode ser aceitável admitir os termos ao vocabulário, tratando os dois como equivalentes que representam o mesmo conceito. Uma nota de escopo deve ser adicionada ao conceito em uma ou ambas as línguas, para esclarecer quaisquer dúvidas.

Não equivalência - Às vezes em uma língua, nenhum termo pode ser encontrado, mesmo que para representar parcialmente ou inexatamente um conceito no vocabulário. Este problema geralmente pode ser resolvido por meio de um termo cunhado ou um termo de empréstimo.

A equivalência em um vocabulário multilíngue que busque seguir os preceitos da transculturalidade, da multiculturalidade e da garantia cultural deve buscar sempre a representação dos conceitos por meio de termos e relações compatíveis com cada língua, recorrendo em caso de não equivalência a estrutura assimétrica, encontrando em outro nível/área do conhecimento o termo equivalente.

Entende-se desse modo, que para a construção de vocabulários controlados multilíngues, todas as línguas são línguas fontes, não devendo em nenhum momento, uma se sobrepor a outra independentemente da 
preponderância maior ou menor que cada uma possua econômica, política ou culturalmente.

O HEREIN Thesaurus é um tesauro multilíngue (nas línguas búlgara, croata, holandesa, inglesa, francesa, alemã, grega, húngara, lituana, polonesa, portuguesa, romena, eslovena e espanhola) que possui estrutura distinta e assimétrica. A Figura 1 exemplifica esse tesauro nas línguas inglesa, francesa, portuguesa e espanhola na representação da área de Sistema Econômico e Financeiro.

\section{Figura 1 - Estrutura distinta e assimétrica no HEREIN Thesaurus}

INGLÊS

class: Group 8 - Economic and financial systems

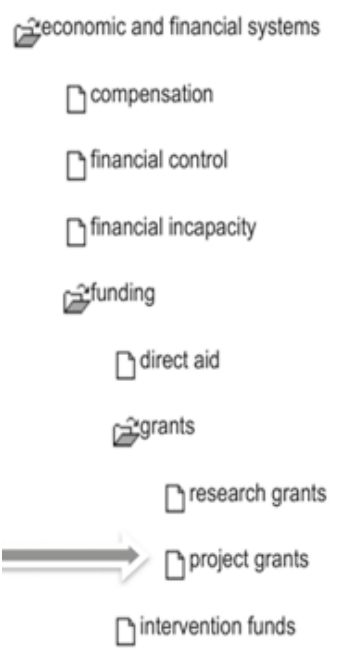

ESPANHOL

class: Groupe 8 - Aspectos económico-financieros

$\mathfrak{Z}^{\text {aspectos económico-financieros }}$

$\square^{\text {pagos compensatorios }}$
$\square^{\text {control financiero }}$
$\square^{\text {incapacidad financiera }}$
$\square^{\text {ayudas directas }}$
$\square^{\text {aysubvenciones }}$
$\square^{\text {ayudas para obras }}$
$\square^{\text {fondos para la conservación }}$

\section{FRANCÊS}

class: Groupe 8 - Système économique et financier

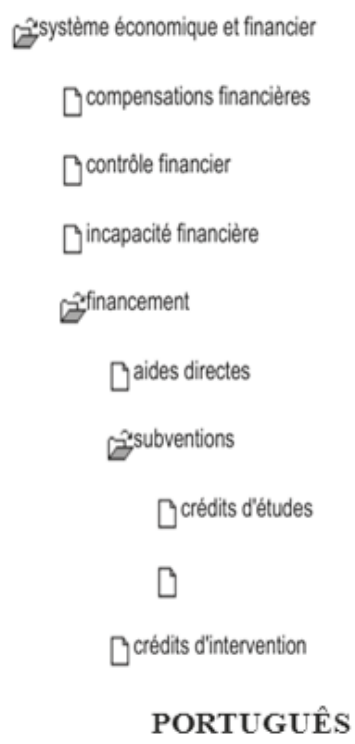

class: Grupo 8 - Aspectos económico - financeiros

izsistema económico e financeiro

Dcompensaçoes financeiras

$\checkmark$ controle financeiro

Dincapacidade financeira

20. financiamento

subsidios directios
$\square^{\text {subsidios de investigaçăo }}$
$\square^{\text {financiamençonto de obras }}$
$\square^{\text {financiamento para a conservação }}$

Fonte: Boccato e Biscalchin (2014, p.245-246) 
Na Figura 1 pode-se observar que o termo Project grants, na língua inglesa, ayudas para obras, na língua espanhola e financiamento de obras, na língua portuguesa não possuem termo correspondente na língua francesa, constituindo-se em um relacionamento assimétrico entre essas línguas. Caso o HEREIN Thesaurus tivesse uma estrutura simétrica e idêntica, seria necessário nesse caso que fosse criado um termo inexistente, o que causaria estranheza aos usuários da língua francesa e perda de eficiência na representação da informação, em função desse termo não existir na língua francesa para a representação dessa área de conhecimento.

Outro tesauro multilíngue que pode ser tomado como exemplo é o AGROVOC, que foi publicado pela Organização das Nações Unidas para a Alimentação e a Agricultura no início da década de 1980 nas línguas inglesa, espanhola e francesa, alcançando 33 línguas em 2019. O AGROVOC é construído de maneira colaborativa por diferentes instituições e busca a representação terminológica por meio de um conceito definido em comum entre todas as línguas. Essa definição conceitual possibilita que a representação terminológica ocorra de maneira assimétrica, pois o termo é representado conforme o contexto de cada língua, compartilhando entre as línguas o conceito da área, não necessariamente a estrutura hierárquica do tesauro.

A aplicação desses cuidados em conjunto com as perspectivas culturais apresentadas, irá possibilitar a construção de um vocabulário multilíngue que atenda a todos os usuários de maneira igualitária e ética, independentemente da língua e/ou contexto cultural em que se encontram inseridos.

\section{Considerações finais}

O uso da estrutura distinta e assimétrica na construção de vocabulários controlados multilíngues, em conjunto com a sua construção simultânea em cada língua envolvida, oferece elementos para que se evite a exclusão de pesquisadores por questões culturais e idiomáticas. Isso colabora também, indiretamente, para evitar que pesquisas e problemas já debatidos por outros pesquisadores, sejam replicados por desconhecimento de sua existência.

Um vocabulário controlado multilíngue que apresente inconsistências, relações hierárquicas ou outras, indevidas e inexistentes, poderá, potencialmente, prejudicar a confiança do usuário no sistema, afetando negativamente a credibilidade da instituição e a disseminação da informação de maneira igualitária e justa a todos os usuários, independentemente da língua de preferência que ele utilize para a realização da busca no sistema. 
A equação do problema é relativamente simples de ser colocada: quanto mais impregnado estiver um vocabulário controlado pelos valores de uma determinada cultura, mais excludente será em relação aos valores que essa mesma cultura não contempla. Atribuir valor, nesse caso, equivale a determinar a importância, a qualidade o mérito dos diversos fatos ou fenômenos culturais.

Em contrapartida, em um vocabulário controlado que possibilite ao usuário identificar-se com os termos, os conceitos e a estrutura relacional nele empregados a relação de confiabilidade do usuário para com o sistema se fortalece pela construção de relação de identidade, contribuindo assim para a disseminação da informação de uma maneira igualitária e justa entre as diferentes culturas e línguas.

Olson (2002, p. 2) afirma que "o catálogo da biblioteca não é uma ferramenta neutra. Ele é construído. Assim, não reflete apenas passivamente os valores dominantes da sociedade de alguma maneira neutra ou objetiva, mas seleciona esses valores com uma expressão." Desse modo, os termos constituintes do catálogo são impregnados de valores tocantes à realidade sócio-histórica-cultural dos responsáveis pela coleta terminológica, que deve se atentar a transculturalidade, a multiculturalidade e a garantia cultural para evitar representações da realidade condizentes com a sua visão particular e cultural de mundo.

De modo sintético, portanto, pode-se afirmar que: a transculturalidade vê as relações entre distintas culturas, em diferentes contextos sócio-histórico-culturais, reconhecendo que as culturas transpõem fronteiras e se comunicam; a multiculturalidade parte da multiplicidade da diversidade cultural dentro de um contexto sóciohistórico-cultural, olhando de uma maneira focalizada cada cultura, ou seja, um país ou um grupo de pesquisadores não possuem apenas uma cultura, mas são influenciados por uma multiplicidade delas e a garantia cultural se preocupa em levar aos usuários termos representativos de sua realidade, afirmando que um termo só é apropriado e útil, se atender aos requisitos, a compreensão, ao contexto do usuário, se preocupando com questões éticas, religiosas e sociais, independentemente de pertencente a um grande ou pequeno grupo de pessoas.

Essa tríade conceitual (transculturalidade, multiculturalidade e a garantia cultural) em conjunto com as normas e estudos científicos sobre construção de vocabulários controlados multilíngues, possibilita que a representação terminológica em cada língua, ocorra conforme o contexto sócio-histórico-cultural de cada usuário.

A combinação desses valores possibilita a recolha terminológica, a construção e o uso de vocabulários controlados de modo condizente com a realidade cultural e linguística dos usuários, apresentando o vocabulário estruturado hierarquicamente em conformidade com a cultura de cada comunidade de usuários. As áreas do conhecimento podem ser 
hierarquicamente idênticas ou de origem e organização totalmente distintas em cada cultura. Com esses valores apresentados, todas essas variações devem ser consideradas na construção de vocabulários controlados multilíngue, de modo a atender os usuários em concordância com a sua cultura e língua, buscando reduzir divergências e barreiras na disseminação e representação da informação impedindo imperialismos linguísticos, políticos e econômicos.

Reconhece-se que a aplicação conjunta dessas perspectivas e normas é complexa em seus aspectos teóricos e aplicados, porém são valiosas para a disseminação da informação de maneira mais igualitária, que possa eliminar ou diminuir consideravelmente a barreira linguística e cultural na busca e localização de informação para a produção de novos conhecimentos. Ao final, o que se pretende com o desenvolvimento de vocabulários controlados multilíngues é igualar as oportunidades e 0 acesso a informação aos pesquisadores de todas as realidades sóciohistórico-culturais representadas nesse sistema de organização do conhecimento.

\section{Referência}

BARITÉ, M. et al. Garantia literária: elementos para uma revisão crítica após um século. Transinformação, Campinas, v. 2, n. 22, p. 123-138, 2010.

BARITÉ, M. Garantía literaria y normas para construcción de vocabularios controlados: aspectos epistemológicos y metodológicos. Scire, [s.l.], v. 15 , n. 2, p.13-24, 2009.

BARITÉ, M. La garantía cultural como justificación en sistemas de organización del conocimiento: aproximación crítica. Palabra Clave (La Plata), Buenos Aires, v. 1, n. 1, p.2-11, 2011.

BEGHTOL, C. A proposed ethical warrant for global knowledge representation and organization systems. Journal of Documentation, London, v. 58, n. 5, p. 507-532, 2002a.

BEGHTOL, C. Ethical decision-making for knowledge representation and organization systems for global use. Journal of the American Society for Information Science and Technology, Ontario, v. 9, n. 56, p.903-912, 15 abr. 2005. Disponível em: www.interscience.wiley.com. Acesso em: 05 abr. 2017.

BOCCATO, V. R. C.; BISCALCHIN, R. As dimensões culturais no contexto da construção de vocabulários controlados multilíngues. Revista Interamericana de Bibliotecología, v.37, n.3, p.237-250, 2014. Disponível 
em:https://aprendeenlinea.udea.edu.co/revistas/index.php/RIB/article/ view/20523. Acesso em: 10 maio 2017.

GARCÍA GUTIÉRREZ, A. La organización del conocimiento en el nuevo orden transcultural: del totalitarismo a la desclasificación (obstáculos epistémicos, regencia de la transcultura y desclasificación). Brazilian Journal of Information Science: research trends, [s.l.], v.8 n.1/2, p.1-34, 2014. Disponível em:

http://www2.marilia.unesp.br/revistas/index.php/bjis/article/view/ 4450/3265. Acesso em: 12 jun. 2017.

GUIMARÃES, J. A. C.; PINHO, F. A. Aspectos éticos em organização e representação do conhecimento (ORC). In: ENCONTRO NACIONAL DE PESQUISA EM CIÊNCIA DA INFORMAÇÃO, 7., 2006, Marília.

Anais[...]Marília: Ancib, 2006. Disponível em:

http://portalppgci.marilia.unesp.br/viewabstract.php?id=265. Acesso em: 13 jun. 2017.

HUDON, M. Accessing documents and information in a world without frontiers. The Indexer, [s.l.], v.21, n. 4, p. 156-159, 1999.

HUDON, M. Multilingual thesaurus construction: integrating the views of different cultures in one gateway to knowledge and concepts. Knowledge Organization, Würzburg, v.24, n. 2, p. 84-91, 1997.

HÜHN, M. et al. (Eds.). Transkulturalität,transnationalität, transstaatlichkeit, translokalität:theoretische und empirische begriffsbestimmungen. Münster; Berlin; London: LIT, 2010.

IFLA. Guidelines for multilingual thesauri. [S.I.]: IFLA, 2009. Disponível em: http://archive.ifla.org/VII/s29/pubs/Profrep115.pdf. Acesso em: 08 jun. 2017.

INTERNATIONAL ORGANIZATION FOR STANDARDIZATION. ISO 25964: information and documentation: thesauri and interoperability with other vocabularies - part 1: thesauri for information retrieval. Genebra: ISO, 2011.

LAZZARIN, L. F. Multiculturalismo e multiculturalidade: recorrências discursivas na educação musical. Revista da ABEM, Porto Alegre, v. 19, p.121-128, mar. 2008.

LEE, J. M. E. Wyndham Hulme: a reconsideration. In: RAYWARD, W. B. (Ed.). The Variety of Librarianship: essays in honour of John Wallace Metcalfe. Sydney: Library Assn. of Australia, 1976. p. 101-113. 
LÓPEZ-HUERTAS, M.J. Gestión del conocimiento multidimensional en los sistemas de organización del conocimiento. In: RODRÍGUEZ BRAVO, B.;

ALVITE DÍAZ, M.A. La interdisciplinariedad y latransdisciplinariedade en la organización del conocimiento científico. León: Universidad de León, 2007. p. 1-26.

LUCCHESI, M. A.; MALANGA, E. B. Interculturais e identidades nacionais: transculturalidade e transdisciplinaridade. Visão Global, Joaçaba, v. 14, n.1, p.73-88, 2011. Disponível em:

http://editora.unoesc.edu.br/index.php/visaoglobal/article/view/868/ pdf_287. Acesso em: 13 jun. 2017.

MILANI, S. O. et al. Os desvios na representação do conhecimento em um contexto multicultural: abordagens teóricas. In: ROMERO, N. L. (ed.). Nuevas perspectivas para la difusión y organización del conocimiento. Valencia: Universidad Politécnica de Valencia, 2009. p. 180-190.

MOODY-ADAMS, M. M. Culture, responsibility, and affected ignorance. Chicago Journals, Chicago, p. 291-309, Jan. 1994. Disponível em: http:// www.jstor.org/stable/2381578. Acesso em: 03 out. 2017.

OLSON, H. A. The power to name: locating the limits or subject representation in libraries. Dordrecht: Kluwer Academic Publisher, 2002.

SANTOS, H. D. Daobjetividade a objetivação: conceitos, categorias e significados. Estatística e Sociedade, Porto Alegre, p.97-111, n.2 nov. 2012.Disponívelem: https://seer.

ufrgs.br/estatisticaesociedade/article/view/36558. Acesso em: 12 jun. 2019. 